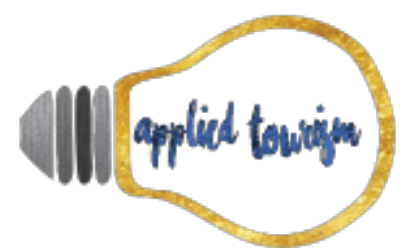

Volume 3, número 1, 2018, p. 58-71

\title{
ROTEIROS TURÍSTICOS DA REGIÃO CENTRAL DO RIO GRANDE DO SUL - Estudo sobre as Principais Características e Atrativos aos Turistas
}

\author{
Dalva Maria Righi Dotto \\ Doutora em Desenvolvimento Regional \\ Universidade Federal de Santa Maria -UFMS \\ dalvadotto@gmail.com \\ Lilian Coradini Cerezer \\ Graduanda em Administração \\ Universidade Federal de Santa Maria -UFMS \\ liliancerezer@hotmail.com \\ Monica Elisa Dias Pons \\ Doutor em Comunicação \\ Universidade Federal de Santa Maria -UFMS \\ monica@ufsm.br \\ Adriele Carine Menezes Denardin \\ Bacharel em Administração \\ Universidade Federal de Santa Maria -UFMS \\ dricadenardin@hotmail.com
}

Recebido: 28 de junho, 2017

Aprovado: 11 de setembro, 2017

\section{RESUMO}

Um roteiro turístico caracteriza-se pela convergência de ações e de atrativos aos turistas numa determinada localidade ou região. Considerado importante para dinamizar o setor de turismo, os roteiros turísticos necessitam ser planejados, organizados e promovidos de forma adequada para atrair os turistas. Nesta perspectiva, este estudo objetiva mapear os roteiros turísticos da Região Central do estado do Rio Grande do Sul (RS) e, mais especificamente, verificar a localização/região em que estão organizados e as características principais destes roteiros. Como procedimento metodológico utilizou-se a abordagem exploratória, com uma pesquisa qualitativa. Observou-se que na região estudada ainda existem poucos roteiros turísticos organizados, com predominância de utilização dos recursos naturais como principal atrativo turístico.

Palavras-chaves: Turismo. Roteiros turísticos. Região Central do Rio Grande do Sul. 


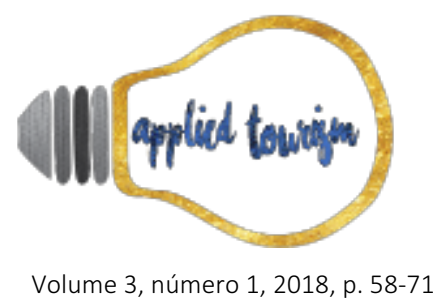

\section{INTRODUÇÃO}

Os motivos para viajar são diversos, desde a antiguidade a necessidade de manter relações entre os diferentes governos, o interesse de relações comerciais e trocas de mercadorias com outros países ou de se deslocar até locais de interesse religioso ou místico motivaram viagens. Atualmente estes motivos foram ampliados e mais do que uma forma de fazer negócios ou buscar momentos de lazer, o turismo representa uma atividade de grande importância que movimenta a economia de muitas localidades, podendo ser uma alavanca para o desenvolvimento de uma região ou país (Rose, 2002). Segundo o autor, o turismo gera divisas e é distribuidor de rendas, gerando empregos, melhorando a qualidade de vida, contribui para a preservação do patrimônio, promove o intercâmbio cultural, ou seja, colabora com o desenvolvimento local.

Nessa perspectiva torna-se importante para as regiões implementarem ações para dinamizar

o setor e, dentre essas ações, a organização de roteiros turísticos mostra-se como uma alternativa relevante. Para o Ministério do Turismo roteiro turístico é um "[...] itinerário caracterizado por um ou mais elementos que the conferem identidade, definido e estruturado para fins de planejamento, gestão, promoção e comercialização turística das localidades que formam o roteiro" (MTur, p.13, 2007) e, segundo Tavares (p. 20-21, 2002), os roteiros turísticos tem sua importância no fato de que "[...] podem ser uma das importantes maneiras de contextualizar atrativos e aumentar o seu potencial de atratividade, o que pode dinamizar o potencial de atração turística da localidade"

Organizados dentro de um espaço geográfico que possua similaridades, os roteiros turísticos sincronizam os fatores envolvidos em uma viagem, ou seja: espaço-tempo, bens e serviços. Nesse sentido, há o espaço físico a ser percorrido, o tempo disponível para usufruir uma programação e para percorrer este espaço, complementados pelos bens e serviços vinculados (Bahl, 1989, apud Ruschmann \& Solha, 2006). 


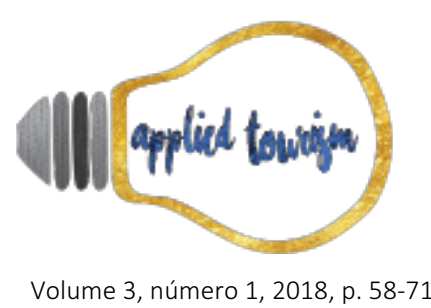

Deve-se mencionar, ainda, que o roteiro atinge um público-alvo, oferecendo um produto passível de consumo e altamente motivador, se exposto de maneira clara e objetiva. Os elementos intervenientes são a adequação do meio de transporte a ser utilizado, em função da distancia a percorrer; os locais a serem visitados, tanto em termos de quantidade, como de qualidade do atrativo; tipo de meios de hospedagem; restaurantes; duração do roteiro; a clientela; e mercado a ser explorado (Bahl, 1989, apud Ruschmann \& Solha, 2006).

Os roteiros turísticos visam o atendimento coletivo, mensurados em fatores que exercem influencia nas pessoas, sendo que a criação de uma empresa de itinerários numa pequena cidade pode ser um elemento altamente facilitador para a atração e fixação de turistas na mesma. Através dos circuitos e serviços que a cidade pode fornecer, destaca-se a possibilidade de torná-las mais atrativas e criativas, através da sua facilidade em encontrar algo que seja realmente único. Deste modo, é possível desenvolver um pequeno nicho de mercado, gerando novas empresas e novos empregos (Bahl, 1989, apud Ruschmann \& Solha, 2006; Tabata, 2007; Gomez \& Quijano, 1999).

No estado do Rio Grande do Sul, com o intuito de adequar a oferta turística e integrar ações para o desenvolvimento do turismo, a Secretaria do Turismo dividiu o Estado em vinte e sete (27) regiões turísticas e, em seu website, cita cento e trinta e quatro (134) roteiros turísticos cadastrados, destacando as rotas turísticas mais importantes que estão em atividade na atualidade (Setel, n.d; Turismo no Rio Grande do Sul, n.d.; Rotas e Roteiros, n.d.).

Neste contexto, este estudo objetiva mapear os roteiros turísticos da Região Central do estado do Rio Grande do Sul (RS) e, mais especificamente, verificar a localização/região e as características principais destes roteiros. Os procedimentos metodológicos utilizados para este estudo foram a abordagem exploratória, através de pesquisa qualitativa realizada em 2016, cujas fontes de consulta foram dados secundários levantados em livros, estudos anteriores, artigos publicados em periódicos e websites institucionais. 


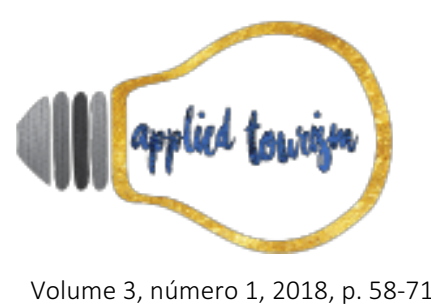

\section{ROTEIROS TURÍSTICOS DA REGIÃO CENTRAL DO RS}

\subsection{Caracterização da Região Central do RS}

Com pequenas cidades que possuem características culturais de seus primeiros moradores, predominantemente imigrantes europeus, tais como Agudo que se apresenta como um reduto da cultura alemã e muitas cidades em que predomina a cultura derivada dos imigrantes italianos, a Região Central do estado do Rio Grande do Sul tem uma grande diversidade de atrativos relacionados à arquitetura, a cultura, a gastronomia e a natureza. Nesta região existe também um acervo dos mais antigos fósseis zoobotânicos do mundo de animais e vegetais com mais de 230 milhões de anos, incluindo o dinossauro mais antigo do mundo, o Staurikossauros Pricei (Setel, n.d; Turismo no Rio Grande do Sul, n.d.; Centro Gaúcho, n.d).

Composta por trinta e quatro (34) municípios, a Região Central do RS incluí os municípios de: Agudo, Cacequi, Cachoeira do Sul, Capão do Cipó, Dilermando de Aguiar, Dona Francisca, Faxinal do Soturno, Formigueiro, Jari, Mata, Nova Esperança do Sul, Nova Palma, Quevedos, Santiago, São João do Polêsine, São Martinho da Serra, Silveira Martins, Tupanciretã, Unistalda, Vila Nova do Sul, Itaara, Ivorá, Jaguari, Júlio de Castilhos, Novo Cabrais, Paraíso do Sul, Pinhal Grande, Restinga Seca, Santa Maria, São Francisco de Assis, São Pedro do Sul, São Sepé, São Vicente do Sul e Toropi (Setel, n.d.). Denominada de coração do Rio Grande, Santa Maria é a principal cidade da região que contrasta com as demais que se caracterizam pela bucolidade do interior (Brasil, n.d.; Setel, n.d.).

Atualmente, segundo a Secretaria Estadual de Cultura, Turismo, Esporte e Lazer (Setel/RS), na Região Central do RS somente onze (11) são considerados municípios turísticos: Agudo; Dona Francisca; Faxinal do Soturno; Itaara; Nova Palma, Restinga Seca, Santa Maria, São João do Polêsine, São Pedro do Sul, São Sepé e Silveira Martins (Setel, n.d.). Destaca-se que estes onze municípios pertencem ao Mapa Brasileiro do Turismo por atender aos novos critérios e exigências do Ministério do Turismo Brasileiro estabelecido em 2016, para a definição de 


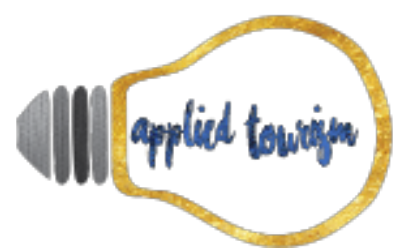

Volume 3, número 1, 2018, p. 58-71

regiões turísticas. A localização geográfica dos municípios turísticos da Região Central do Rio Grande do Sul / Brasil está representada na Figura 01.

Figura 01. Região Turística Central do Rio Grande do Sul, Brasil.

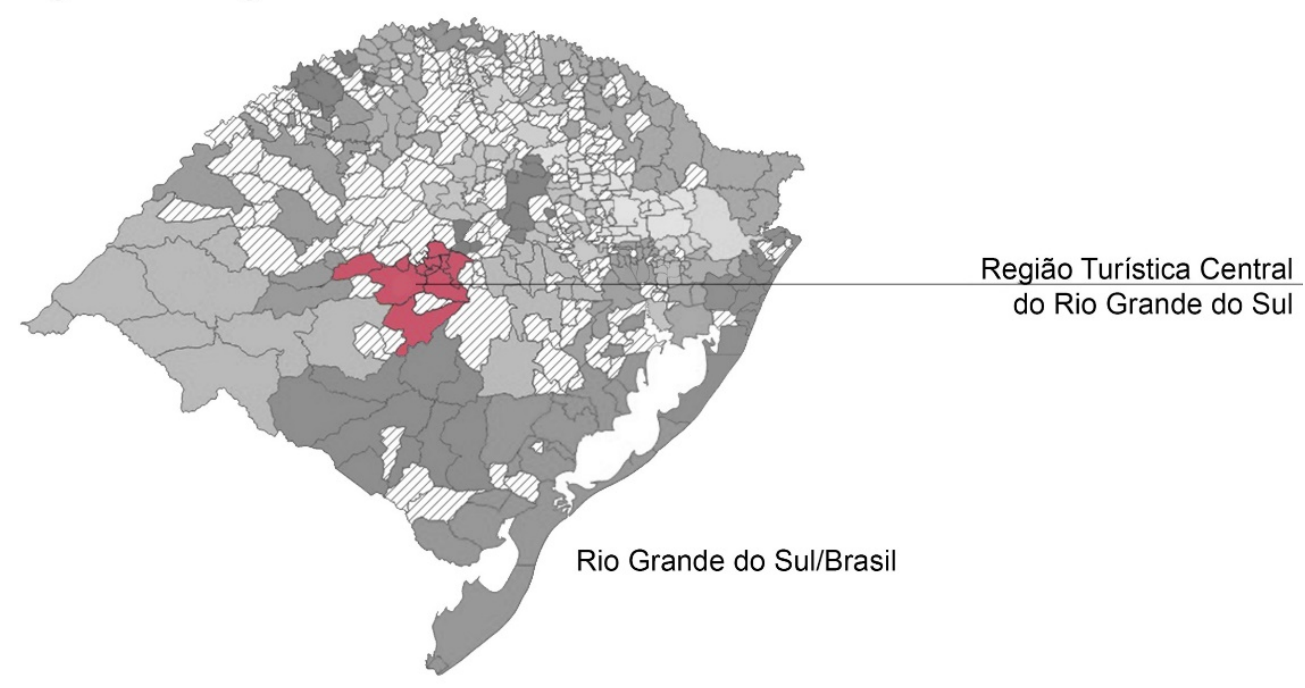

Fonte: Adaptado de Setel (2016).

\subsection{Principais Roteiros Turísticos da Região Central do RS}

Os roteiros turísticos organizados na Região Central do Estado e divulgados mais amplamente são os denominados Santos Caminhos da Fé, Roteiro Arte \& Religiosidade, Roteiros Integrados da Quarta Colônia, Rota Turística e Gastronômica Santa Maria/Silveira Martins, Jardim das Esculturas, Rota Paleontológica e Território do Sagrado, cujas localizações e características principais estão descritas a seguir.

a) Santos Caminhos da Fé

Localização: municípios de São João do Polêsine, São Pedro do Sul, São Vicente do Sul, Santiago, São Borja, São Miguel das Missões, São Luiz Gonzaga, Santa Rosa e Santo Ângelo.

Características: roteiro entre cidades com nomes de Santos, que estimulam o turismo cultural e religioso de Santa Maria e da região Centro-Fronteiriça, com início na Basílica da 


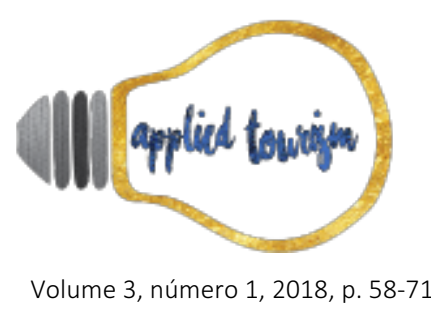

Medianeira, em Santa Maria. Neste local o turista-peregrino recebe um documento denominado de passaporte da fé e, na sequência, durante oito dias, visita templos religiosos e atrativos histórico-culturais nos municípios integrantes, sendo que o peregrino recebe uma bênção, conhece mais sobre religiosidade, espiritualidade e cultura locais e, ao final, tem carimbado seu passaporte, recebendo o certificado de Peregrino dos Santos Caminhos da Fé (Turismo no Rio Grande do Sul, n.d.; Santa Maria, 2016a; Centro Gaúcho, 2016).

b) Roteiro Arte \& Religiosidade

Localização: município de Santa Maria.

Características: através de um passeio autoguiado, com a utilização de um áudio-fone, este roteiro contempla visitas nas principais Igrejas Católicas locais. As informações repassadas aos turistas incluem a história das Igrejas e interpretações das principais obras nelas contidas. As Igrejas participantes do projeto são a Catedral Metropolitana de Nossa Senhora Imaculada Conceição, o Santuário Basílica da Medianeira e a Igreja Nossa Senhora das Dores (Turismo no Rio Grande do Sul, n.d.; Santa Maria, 2016b; Centro Gaúcho, 2016).

c) Roteiros Integrados da Quarta Colônia

Localização: municípios integrantes da Quarta Colônia: Agudo, Dona Francisca, Faxinal do Soturno, Ivorá, Pinhal Grande, Restinga Seca, São João do Polêsine e Silveira Martins.

Características: destaca-se que a região denominada de Quarta Colônia recebeu este nome por ser a quarta localidade que foi colonizada pelos imigrantes italianos no Brasil, sendo que atualmente é povoada, em sua maioria, por descendentes destes imigrantes e que conservam sua cultura, nas mais diversas manifestações, tais como gastronomia, realização de eventos e religiosidade. Entretanto, esta região preserva, além de evidências de imigrantes italianos, também de imigrantes alemães e traços das tradições indígenas, de portugueses e afro-descendentes. Estas marcas - materiais e imateriais - constituem um patrimônio que, na sua diversidade (natural e cultural) dá sentido às formas de ser e de fazer do seu povo (Turismo no Rio Grande do Sul, n.d.; Rotas e Roteiros, n.d.). 


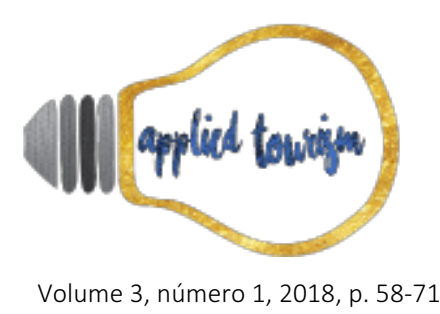

Uma opção de roteiro é a caminhada noturna de 520m no Monte Grappa (todo iluminado), no município de Ivorá, que recebeu esta denominação por recordar o famoso monte de mesmo nome da Itália. No percurso, além das belezas naturais, há uma Via Sacra composta por 15 capitéis e culmina numa Capela em homenagem a Nossa Senhora Della Guardia. Outra opção é conhecer o acervo com mais de 50 mil nomes de imigrantes italianos do Centro de Pesquisas Genealógicas de Nova Palma, cujo responsável é o Padre Luiz Sponchiado. Este Centro é referência para pesquisadores de todo o país e do Exterior e representa um relevante trabalho de resgate das origens, memória e cultura do povo da Região Central do Estado (Turismo no Rio Grande do Sul, n.d.; Rotas e Roteiros, n.d.).

\section{d) Rota Turística e Gastronômica Santa Maria / Silveira Martins}

Localização: entre os municípios de Silveira Martins e Santa Maria.

Características: segundo Stecker (p. 72, 2010) nesta rota "todos os locais visitados representam o patrimônio existente, como a gastronomia, a arquitetura, a arqueologia, a cultura e o saber-fazer". Dentre as diversas opções de rota turística destaca-se o Caminho da Uva e das Águas, que envolve as comunidades de Val de Buia e Val Feltrina, no município de Silveira Martins. Nesta rota os visitantes realizam passeios para desfrutar belas paisagens de morros e vales, onde se destacam as cascatas, os balneários e os belvederes presentes. Também são realizadas visitas às propriedades rurais com tradição centenária de produção de uvas, sendo que nestas propriedades os turistas podem usufruir de experiências gastronômicas com consumo e aquisição de produtos denominados coloniais por serem produzidos artesanalmente nestas propriedades, tais como vinho, massas, cachaça e hortifrutigranjeiros (Turismo no Rio Grande do Sul, n.d.; Rotas e Roteiros, n.d.).

Faz parte deste roteiro o Conjunto Histórico da Pompéia, no interior do município de Silveira Martins que possui uma Capela construída pelo italiano Vincenzo Guerra, em 1907, cujos traços arquitetônicos foram inspirados em igrejas italianas. Neste município, no que se refere à gastronomia, há restaurantes e cantinas que oferecem aos turistas refeições com 


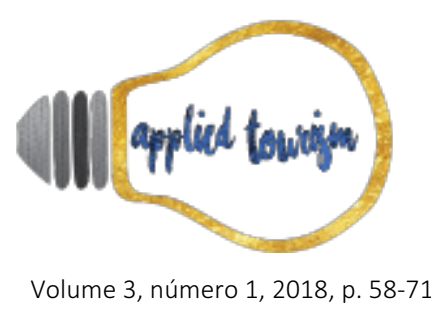

culinária típica que representa os hábitos dos descendentes de italianos que neste local residem (Rotas e Roteiros, n.d.).

No município de Santa Maria, integra este roteiro, visitas agendadas às fábricas de facas existentes, principalmente, no distrito de Arroio Grande, cuja produção contempla processos que utilizam técnicas artesanais clássicas, juntamente com tecnologia contemporânea. Nestes locais existem show room e espaço de comercialização dos produtos (Rotas e Roteiros, n.d.).

e) Jardim das Esculturas

Localização: municípios de Nova Palma e Júlio de Castilhos.

Características: considerado o maior espaço de esculturas em pedra de arenito na América Latina esculpida por um único artista, o Jardim das Esculturas é composto por uma exposição de mais de 500 obras do escultor Rogério Bertoldo, incluindo esculturas em pedra e madeira, com temáticas variadas, que são expostas em uma área verde de aproximadamente $6.000 \mathrm{~m}^{2}$. Para complementar o roteiro, o turista tem a opção de incluir uma trilha de 1,2 km, com esculturas e um arvorismo que leva para Montanha do Silêncio, onde se encontra a maior escultura do artista, que possui aproximadamente 6 metros de altura e 40 toneladas. Também compõem este atrativo a Rota das Esculturas com aproximadamente, 9 quilômetros entre a cidade de Nova Palma e o Jardim das Esculturas. A Rota é composta por 12 esculturas que remetem à cultura italiana (Nova Palma, n.d.; Centro Gaúcho, 2016; Jardim das Esculturas, n.d.).

\section{f) Rota Paleontológica}

Localização: municípios de Santa Maria, São Pedro, Mata e São João do Polêsine.

Características: nos acervos dos museus desta rota é apresentada a história de fósseis vegetais e animais, além da possibilidade de apreciar originais e réplicas destes. Ressalta-se que em 1902 foi descoberto no município de Santa Maria o primeiro vertebrado fóssil 


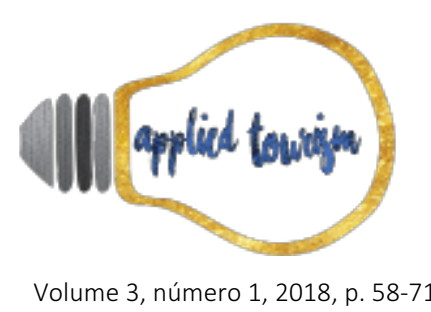

Triássico da América Latina, sendo que neste território existem marcas de um passado com mais de 200 milhões de anos, representado por fósseis de variadas espécies de dinossauros e de florestas gigantes que existiram no período Triássico (Brasil, 2014; Centro Gaúcho, 2016).

Os principais pontos de visitação deste roteiro incluem: (a) no município de Santa Maria o Museu Educativo Gama D $\backslash$ 'Eça, o Laboratório de Estratigrafia e Paleobiologia da Universidade Federal de Santa Maria - UFSM e o afloramento da Bela Vista, onde é possível entender diferentes formações geológicas: (b) no município de São João do Polêsine, o Centro de Apoio as Pesquisas Paleontológicas - CAPPA/UFSM, local em que estão as últimas descobertas de animais fossilizados (vertebrados), achados na região da Quarta Colônia; (c) no município de São Pedro do Sul, que possui muito fósseis vegetais, destaca-se o fóssil de um "dicinodonte" herbívoro, encontrado neste município em 1929, cuja réplica do cranio está no município e o original, atualmente está no Museu de Tubingen - Alemanha; Sítio da Piscina e Sítio da Carpintaria, onde se observa os afloramentos de fósseis e de espécies de coníferas, da antiga floresta do Triássico. Neste município os turistas também podem apreciar o Complexo Turístico denominado Raízes de Pedra, localizado em área rural e com fósseis vegetais que afloram no local; o Museu Arqueológico e Paleontológico Walter Ilha com fósseis coletados na região; e o Monumento Paleobotânico de Água Boa, com fósseis de "ginkófitas", considerados fósseis vivos. (d) no município de Mata, que possui um relevente patrimonio paleobotânico formado por troncos, raízes, galhos e liquens fossilizados, podem ser visitados o Jardim Paleobotânico, o Museu Pe. Daniel Cargnin, com acervo fóssil de animais vertebrados, e praças e monumentos construídos com fósseis vegetais, tais como a Escadaria da Igreja Matriz Santo Antonio e a Gruta de Nossa Senhora de Lourdes (Turismo no Rio Grande do Sul, n.d.; Centro Gaúcho, 2016).

\section{g) Território do Sagrado}

Localização: municípios integrantes da Quarta Colônia: Agudo, Dona Francisca, Faxinal do Soturno, Ivorá, Pinhal Grande, Restinga Seca, São João do Polêsine e Silveira Martins. 


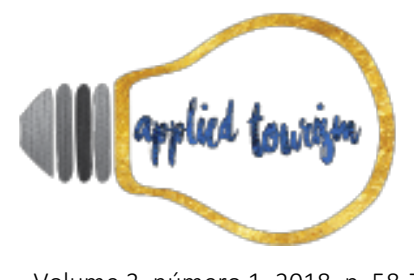

Volume 3, número 1, 2018, p. 58-71

Características: com ênfase no turismo religioso, esta rota contempla passeios que incluem visitas a igrejas e santuários da região, com grande diversidade de estilos arquitetônicos. Destaca-se, no município de Santa Maria a Catedral Metropolitana Nossa Senhora da Conceição (1909), o Santuário Nossa Senhora Medianeira (1980), a Igreja Nossa Senhora das Dores (1944), o Santuário de Schoentast (1948) e a Capela de São Francisco de Assis (2015). Em São João do Polêsine, a Igreja Matriz de Corphus Cristhi (1886), em Silveira Martins a Igreja Santo Antônio de Pádua (1890) e, em Faxinal do Soturno, a Ermida de São Pio de Pietrelcina (2004) (Rotas e Roteiros, n.d.; Centro Gaúcho, 2016).

\section{h) Outros roteiros}

Além dos roteiros acima descritos, na região de estudo existem roteiros de menor impacto, organizados de forma mais precária e com menor procura por parte dos turistas, tais como as caminhadas, trekking e trilhas ecológicas, com opções de caminhadas de curta e longa distância em ambiente natural, com trilhas, obstáculos ou escaladas, subida em paredões rochosos com equipamento especial nos municípios de Santa Maria e Silveira Martins; a trilha no Monte Grappa no município de Ivorá; a trilha da Gruta do Índio, no município de Nova Palma ou a trilha na Quinta Dom Inácio com rappel, tracking e cascading no município de Silveira Martins. Também existe o roteiro que prevê percorrer a pé o Distrito de Vale Vêneto, no município de São João do Polêsine ou realizar um passeio de barco com vista da Pedra do Paga Peão, no município de Pinhal Grande (Santa Maria, 2016c; Rotas e Roteiros, n.d.; Centro Gaúcho, 2016).

\section{CONSIDERAÇÕES FINAIS}

Diante do exposto conclui-se que os principais roteiros da Região Central do Rio Grande do Sul estão presentes, principalmente, nos municípios de Nova Palma, Santa Maria e Silveira Martins. Também se constatou que as características predominantes dos roteiros estudados referem-se aos atributos da natureza, que tem presença destacada em todos os roteiros apontados nesta pesquisa e a cultura italiana, principalmente a gastronomia, a religiosidade 


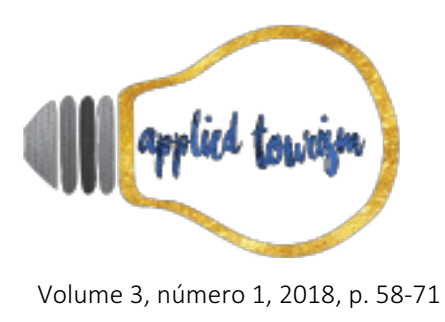

e a arquitetura. De forma ampla pode-se afirmar que alguns destes roteiros apresentam a tentativa de proporcionar aos visitantes um voltar/reviver os hábitos da época da chegada dos imigrantes italianos a este território.

Como contribuições gerenciais deste estudo sobre roteiros turísticos deve-se ressaltar que as atividades relacionadas ao setor de turismo devem, segundo Sousa (2015), harmonizar os interesses e as perspectivas dos (i) turistas (satisfação de suas necessidades e desejos), (ii) das organizações prestadoras de serviços (lucros com suas atividades), (iii) da comunidade onde se localiza o destino turístico (geração de emprego e intercâmbio cultural) e (iv) dos agentes dos governos (geração de riqueza e desenvolvimento da região).

A investigação e o aprofundamento acerca da gestão dos roteiros turísticos podem contribuir de forma significativa na identificação da motivação da escolha de determinado roteiro turístico (Pearce, 2011), na adequação das ações e na atratividade de turistas, revertendo em consequências positivas no desempenho destes.

Também se destaca que a diversidade das atividades propostas, juntamente com a organização do roteiro, tem papel significativo na escolha e no usufruto de determinado roteiro por parte dos turistas, o que torna relevante a adequação do espaço físico a ser percorrido e os bens e serviços presentes no roteiro. Neste quesito torna-se relevante a inclusão de ações estratégias de marketing, com a definição dos segmentos de público alvo de turistas a serem contemplados/atraídos, e a consequente satisfação de suas necessidades e desejos (Kotler \& Keller, 2006; Boone \& Kurtz, 2009). Acrescenta-se a divulgação que deve ser realizada visando à criação de imagem positiva, incluindo a cooperação dos agentes envolvidos, tais como poder público, especialistas na área e empresas turísticas (Mougey, 2009), sendo que na criação da imagem é preciso considerar que esta "é um processo subjetivo, único, relacionado à experiência individual e, ao mesmo tempo, somatório de sensações, percepções e inter-relações de atores locais" (Almeida, 2009). 


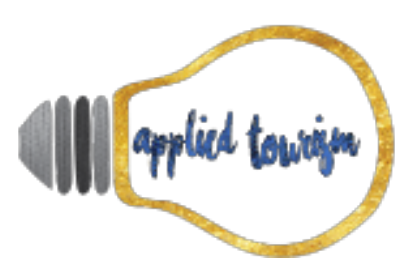

Volume 3, número 1, 2018, p. 58-71

Nesta perspectiva, os resultados encontrados neste estudo corroboram a afirmativa de que é importante identificar as principais características dos roteiros turísticos, pois estas servem de propulsores para atrair segmentos específicos de turistas que apreciam as atividades e as peculiaridades nele presentes. Esta caracterização confere ao roteiro uma identidade única que, segundo o MTur (2007), deve ser utilizada na gestão do roteiro, adequando seu planejamento, promoção e comercialização.

Outro quesito relevante, segundo alguns autores como Rose (2002), Tabata (2007) e Tavares (2002), é a possibilidade de que roteiros turisticos que sejam geridos de forma adequada e que atraem muitos turistas podem contribuir para o desenvolvimento das regiões onde estão inseridos. Com esta perspectiva, pode-se inferir que há potencial para atrair diferentes segmentos de turistas na região objeto deste estudo e que, no intuito de incrementar o desenvolvimento desta região, a organização de roteiros pode ser ampliada e, consequentemente, ter mais representatividade, motivando os turistas a visitação das inúmeras e diversificadas atrações existentes.

\section{REFERÊNCIAS}

Almeida, A.L.C. (2009). Identidade, imagem e reputação organizacional: conceitos e dimensões da práxis. In Kunsch, M.M.K. Comunicação organizacional: linguagem, gestão e perspectivas. São Paulo: Saraiva.

Bahl, M. A (1989). Fundamentação do turismo no planejamento de roteiros turísticos. Boletim Técnico do SENAC, Rio de Janeiro, v. 15.

Boone L.E., Kurtz, D.L. (2009). Marketing Contemporâneo. São Paulo, São Paulo: Cengage Learning.

Brasil (n.d.). Portal da Cidadania. Região Central RS. O territorio. Retirado de http://www.territoriosdacidadania.gov.br/dotlrn/clubs/territriosrurais/regiocentralrs/onecommunity?page_num $=0$.

Centro Gaúcho (2016). Retirado de https://www.turismoregiaocentralrs.com/rotas-e-roteiros.

Gomez, J., Quijano, C. (1999). Rutas e Itinerarios Tuisticos En España. Madrid: Editorial Sintesis.

Jardim das Esculturas (n.d.). Retirado de http://www.jardimdasesculturas.com.br.

Kotler, P., Keller, K.L. (2006). Administração de marketing. 12. ed. São Paulo: Pearson Prentice Hall. 


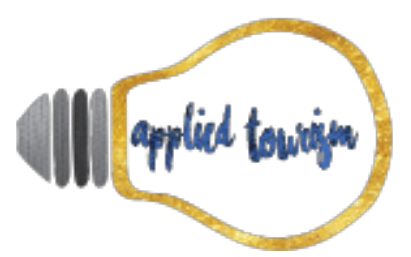

Volume 3, número 1, 2018, p. 58-71

Mougey, J. (2009). Quelques considérations générales sur tourisme et la culture cit in Culture,Tourisme et Développement Cluzeau, Claude et Tobelem, Jean-Michael 2009 Paris L'Harmattan. Paris: L'Harmattan.

MTur - Ministério do Turismo (2007). Roteirização turística. Série Roteiros do Brasil. V.7. Brasília: Secretaria Nacional de Políticas de Turismo.

Nova Palma (n.d.) Retirado de www.novapalma.rs.gov.br.

Pearce, P.L. (2011). Travel motivation, benefits and constraints to destination. In: Destination, marketing and manaagement, Theories an applicatios: CABI.

Brasil (2014). Portal Brasil. Conheça a rota paleontológica do Rio Grande do Sul. Retirado de http://www.brasil.gov.br/turismo/2014/12/conheca-a-rota-paleontologica-do-rio-grandedo-sul.

Rose, A. T. de. (2002). Turismo: planejamento e marketing, aplicação da matriz de portfólio para destinações turísticas. Barueri, SP: Manole.

Rotas e Roteiros (n.d) - Rotas e Roteiros do Turismo Receptivo Gaúcho. Retirado de http://rotaseroteiros.com.br.

Ruschmann, D., Solha, K. T. (2006). Planejamento turístico. Barueri, SP: Manole.

Santa Maria. Prefeitura Municipal Santa Maria (2016a). Santos Caminhos da Fé. Retirado de http://www.santamaria.rs.gov.br/turismo/215-santos-caminhos-da-fe.

. Prefeitura Municipal Santa Maria (2016b). Turismo de Aventura http://www.santamaria.rs.gov.br/turismo/299-roteiro-arte-amp-religiosidade.

. Prefeitura Municipal Santa Maria (2016c). Turismo de Aventura https://www.santamaria.rs.gov.br/economico/489-turismo-de-aventura.

Setel (2016). Secretaria do Turismo Esporte e Lazer do Rio Grande do Sul. Mapa da Região Turistica Central. Retirado de http://www.setel.rs.gov.br/conteudo/3461/mapa-da-regiao-turisticacentral.

Setel (n.d.). Secretaria do Turismo Esporte e Lazer do Rio Grande do Sul. Retirado de http://www.setel.rs.gov.br.

Sousa, A.C. (2015). O proceso histórico da atividade turística mundial e nacional. Cadernos da FUCAMP, v.14, n.21.

Stecker, D.T. (2010). Rota turística e gastronômica Santa Maria - Silveira Martins: o desenvolvimento do turismo na Quarta Colônia de imigração italiana. Dissertação de Mestrado Profissional Programa de Pós-Graduação em Patrimônio Cultural, Universidade Federal de Santa Maria.

Tabata, R. (2007). Tematic Itenaries: An Approach to Tourism Product Development. Manoa: University of Hawaii. 


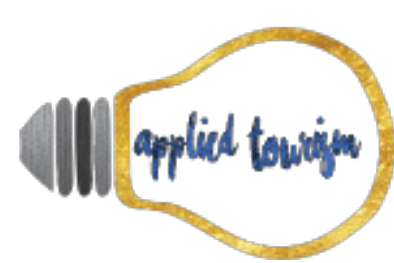

Volume 3, número 1, 2018, p. 58-71

Tavares, A. M. (2002). City tour. São Paulo: Aleph.

Turismo no Rio Grande do Sul (n.d.) Retirado de http://www.turismo.rs.gov.br/roteiros/ 